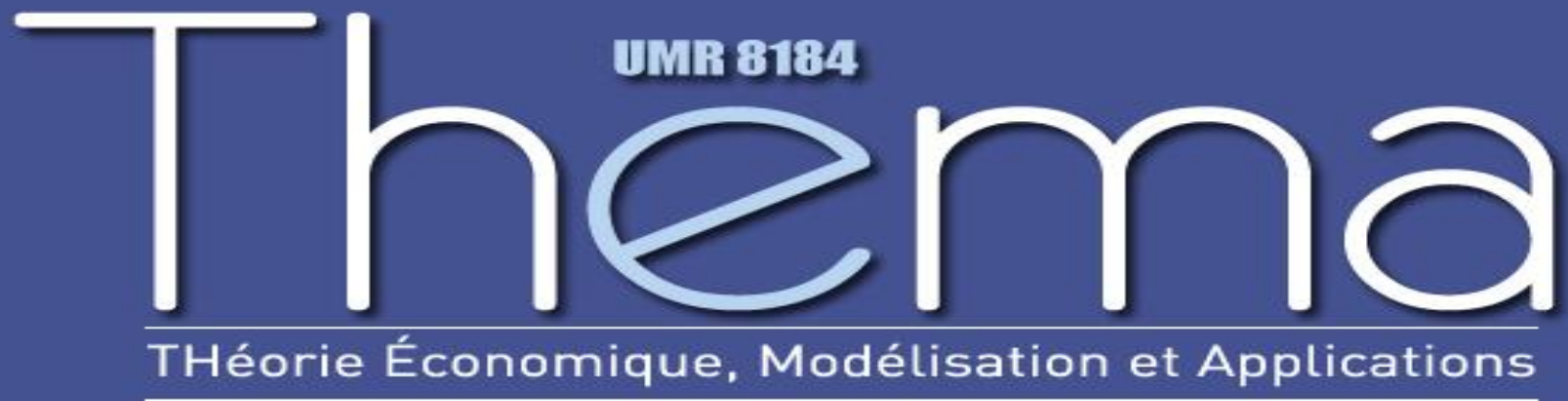

Thema Working Paper $n^{\circ} 2009-16$ Université de Cergy Pontoise, France

A repeat sales index robust to small datasets

Baroni Michel Barthélémy Fabrice Mokrane Madhi

December, 2009 


\title{
A repeat sales index robust to small datasets
}

\author{
Michel Baroni*, Fabrice Barthélémy ${ }^{\S}$, Mahdi Mokrane ${ }^{\ddagger}$
}

\begin{abstract}
As suggested by D. Geltner, commercial properties indices have to be built using repeat sales instead of hedonic indices. The repeat sales method is a means of constructing real estate price indices based on a repeated observation of property transactions. These indices may be used as benchmarks for real estate portfolio managers. But the investors in general are also interested in introducing real estate performance in their portfolio to enhance the efficient frontier. Thus, expected return and volatility are the two key parameters. To create and to improve contracts on real estate indices, trend and volatility of these indices must be robust regarding to the periodicity of the index and the volume of transactions.
\end{abstract}

This paper aims to test the robustness of the trend and volatility estimations for two indices: the classical Weighted Repeat Sales (Case \& Shiller 1987) and a PCA factorial index (Baroni, Barthélémy and Mokrane 2007). The estimations are computed from a dataset of Paris commercial properties.

The main findings are the trend and volatility estimates are biased for the WRS index and not for the PCA factorial index when the periodicity increases. Consequently, the level of the index at the end of the computing period is significantly different for various periodicities in the case of the WRS index. Globally, the PCA factorial seems to be more robust to the number of transactions.

Firstly, we present the two methodologies and then the dataset. Finally we test the impact of the number of transactions per period on the trend and volatility estimates for each index and we give an interpretation of the results.

Keywords: Repeat sales indices, Index estimations, Transactions volume.

JEL Classification Code: C20, G00

\footnotetext{
* ESSEC Business School, Avenue Bernard Hirsch - B.P. 105, 95021, Cergy-Pontoise Cedex, France, Tel.: +33 (0) 1344330 92. Email: baroni@essec.fr

${ }^{\S}$ Université de Cergy-Pontoise, THEMA, 33Bd du Port, F-95000, Tel.: +33 (0)1 342562 53. Email: fabrice.barthelemy@u-cergy.fr

‡ AEW EUROPE, 1-3 rue des Italiens, 75009 Paris, France, Tel.: +33 (0)1 784092 60. Email: mahdi.mokrane@aeweurope.com
} 


\section{Introduction}

The repeat sales method is a means of constructing real estate price indices based on a repeated observation of property transactions. The method begins by stating that the price of a good $i$ at date $t$ is a function of four terms: the good's quality at date $t$, the value of the underlying global real estate index at date $t$, a random walk variable linked to good $i$ at date $t$ and an error term, here again linked to good $i$ at date $t$ (modeled as a white noise). Case and Shiller (1987) generalize the work of Bailey, Muth and Nourse (1963) and thus provide the first approach of repeat measures methods for construction of real estate indices.

The main merit of this model based on repeat sales is that it does not presuppose any mechanical form for the behavior of the underlying real estate index. Since 1987, the model has attracted a lot of attention and has given rise to a number of improvements or critics in the following five topics ${ }^{1}$ :

\section{i) The constant quality assumption}

Goetzmann and Spiegel (1995) find a consistent bias in the index resulting from repeat sales regressions and suggest that it is caused by incremental home improvements, as well as by price risk. They propose a maximum likelihood method for estimating the first and second moments of the fixed and temporal components of real estate returns that relies upon relatively small samples. Shiller (1998) picks out the constant quality assumption and focuses on the market heterogeneity to explain the bias introduced in the regressions coefficients.

\section{ii) The selection bias}

Case et al. (1997), Gatzlaff and Haurin (1997), Quigley (1995), Meese and Wallace (1997), Englund, Quigley and Redfearn (1998), and more recently Hwang and Quigley (2004) have emphasized the bias due to the selection of properties induced by the methodology itself. The properties that are sold more frequently are over-represented and can introduce a bias that may be all the more important since the samples are small.

\section{iii) The revision issue}

Shiller (1998)², Clapp and Giaccotto (1997), Clapham et al. (2006) consider the revision due to adding new data in the dataset may cause substantial concern for the stability of the index. They

\footnotetext{
1

See Baroni et al. (2005) for a presentation of these improvements suggested in the literature along four issues (constant quality assumption, selection bias, revision issue, heteroscedasticity).
} 
measure this impact empirically from various dataset. Baroni et al. (2008) notice this impact is more significant for periods when the number of observations is smaller.

iv) The presence of heteroscedasticity

Abraham and Schauman (1991), Case and Shiller (1987, 1989), Clapp and Giaccotto (1999), Englund et al. (1998), Goodman and Thibodeau (1995, 1998) and Meese and Wallace (1997) reveal the presence of heteroscedasticity in the error terms of the regression. This hederoscedasticity may be reduced using various methods depending on the factors that explain it.

\section{v) The small transaction volume issue}

Goetzmann (1992) analyses the behavior of the estimator when the number of observations is small relative to the length of the return series to be estimated. In this case, the columns of the explanatory variables matrix tend to be nearly the same. Goetzmann suggests using the Bayes and Stein method to minimize the bias induced by multi-collinearity, and compares it to the repeat sales Bayes estimator (which encompasses the traditional ridge regression). Moreover, he underlines the fact that even if this econometric approach is consistent (asymptotical concept), it leads to a negative autocorrelation in the estimated return series.

In order to avoid the traditional time dimension, which clearly exhibits the lack of observations, McMillen and Dombrow (2001) treat the time as a continuous time and use a flexible Fourier expansion, which leads to an efficient estimation of the price index whatever the number of observations. Nevertheless, this approach remains sensitive to the initial observations that greatly influence the index.

Let us notice that this small transactions volume issue is also linked to the periodicity, in the sense that, for a given dataset, the higher the periodicity is, the less the transaction volume by period.

The aim of this paper is to show that another methodology using repeat sales proposed by Baroni et al. (2007) leads to a more robust index estimation even in the case of small transactions volume. Firstly, we compare it with the classical WRS methodology. Then we describe a dataset of transactions of commercial properties in Paris we will use to test the relative robustness of the two indices. The robustness is considered in two ways: firstly for the index itself, secondly for the risk and return measures induced by the index. Let us notice that the purpose of measuring the risk was present in Goetzmann (1992).

2

See chapter 8 


\section{The Repeat-sales indices}

\subsection{The methodologies}

The repeat-sales indices are computed from recorded transactions of properties for which the dates and the prices of the initial acquisition and the resale are available. We start by presenting below the two methodologies we are going to compare:

The classical WRS methodology assumes that the price of an asset $i$ at date $t$ is a function of four terms: the asset's quality at date $t$, the value of the underlying global real estate index at date $t$, a random walk variable linked to asset $i$ at date $t$ and an error term, here again linked to asset $i$ at date $t$ (modeled as a white noise). Case and Shiller (1987) generalize the work of Bailey, Muth and Nourse (1963) and thus provide the first approach of repeat measures methods for construction of real estate indices. The main merit of this model based on repeat sales, is that it does not presuppose any mechanical form for the behavior of the underlying real estate index.

- The factorial repeat sales index constructed from economic and financial variables (see Baroni, Barthélémy and Mokrane, 2007). Real estate price returns are computed from the repeat sales transactions and are associated with their corresponding returns for the economic and financial variables. Hence for each observation composed of two transactions of a same asset, a returns vector is constructed. Then, each real estate return is explained by the other returns, using a linear regression. Finally, the index is constructed from the factors time series, which are determined by a principal component analysis as a linear combination of variables.

For both methodologies, we should then notice that the dates $t$ and $\tau$ are given in a theoretical point of view. The overall period of analysis may be sliced into $S$ subperiods. 
One refers to date $\tau$ for the acquisition date, denoted $T_{1}(i)$ for observation $i$, and to $t$ as the resell date, denoted $T_{2}(i)$ for observation $i$. By aggregating the observations (a buy or sell transaction) by subperiod, one may construct a discontinuous series. The interval $\left[\underline{t}_{s}, \bar{t}_{s}\left[\right.\right.$ represents the $s^{\text {th }}$ subperiod. For each transaction $i$, the corresponding price returns for the $k$ variables are computed for the period that covers $T_{1}(i)$ to $T_{2}(i)$, the holding period. The $k$ factors of a PCA on these $k$ series of corresponding returns (in logarithm) are computed to avoid collinearity. Let $V_{\alpha}$ the $\alpha^{\text {th }}$ PCA factor of dimension $n \times 1$, where the element $V_{\alpha}(i)$ corresponds to observation $i$. The various (one for each factor) linear combination of the $k$ time series from which the corresponding returns are computed makes possible the computing of the time series of factors, denoted $\forall s=2, \ldots, S, F_{\alpha}(s)$.

The links and the differences of the two approaches are presented in Table 1 below.

\begin{tabular}{|c|c|c|}
\hline & WRS & PCA \\
\hline $\begin{array}{c}\text { Explanatory } \\
\text { Variables }\end{array}$ & $\begin{array}{l}\qquad D: n \times(S-1) \\
\text { where } D_{s}(i) \text { is: } \\
\left\{\begin{array}{c}-1 \text { if the first sale date belongs to the } s^{\text {th }} \text { period, } \\
+1 \text { if the resell date belongs to the } s^{t h} \text { period, } \\
0 \text { in the other cases. }\end{array}\right.\end{array}$ & $\begin{array}{l}\qquad V: n \times(k+1) \\
\text { where } V_{\alpha}(i) \text { is: } \\
\left\{\begin{array}{c}1 \text { if } \alpha=1 \text { (the constant), } \\
\text { ln of the corresponding return of the } \alpha^{\text {th }} P C A f a c t o r\end{array}\right.\end{array}$ \\
\hline $\begin{array}{c}\text { Model } \\
\operatorname{LnR}(i) \\
\forall i=1, \ldots, n\end{array}$ & $\sum_{s=2}^{S} \Phi_{s} D_{s}(i)+\varepsilon(i)$ & $\delta+\sum_{\alpha=1}^{k} \beta_{\alpha} V_{\alpha}(i)+\varepsilon(i)$ \\
\hline $\begin{array}{l}\text { Estimation } \\
\quad \operatorname{LnR}(i) \\
\forall i=1, \ldots, n\end{array}$ & $\sum_{s=2}^{S} \hat{\Phi}_{s} D_{s}(i)$ & $\hat{\delta}+\sum_{\alpha=1}^{k} \hat{\beta}_{\alpha} V_{\alpha}(i)$ \\
\hline $\begin{array}{l}\text { Return } \\
\text { Estimation } \\
\quad \operatorname{LnR}(s) \\
\forall s=2, \ldots, S\end{array}$ & $\hat{\Phi}_{s}-\hat{\Phi}_{s-1}$ & $\hat{\delta}+\sum_{\alpha=1}^{k} \hat{\beta}_{\alpha} \ln \left(\frac{F_{\alpha}(s)}{F_{\alpha}(s-1)}\right)$ \\
\hline $\begin{array}{l}\text { Index } \\
\text { Estimation } \\
\\
\quad \hat{i}(s) \\
\forall s=2, \ldots, S\end{array}$ & $\begin{array}{c}100 \times \exp \left(\hat{\Phi}_{s}\right)=\hat{i}_{s-1} \times \exp \left(\hat{\Phi}_{s}-\hat{\Phi}_{s-1}\right) \\
\text { with } i_{1}=100\end{array}$ & $\hat{i}_{s-1} \times \exp \left(\hat{\delta}+\sum_{\alpha=1}^{k} \hat{\beta}_{\alpha} \ln \left(\frac{F_{\alpha}(s)}{F_{\alpha}(s-1)}\right)\right.$ \\
\hline
\end{tabular}

Table 1: comparison of the two repeat sales methodologies 
We notice that for WRS, the number of explanatory variables is directly related to the number of periods. On the contrary for the PCA factorial index, this number is fixed and the periodicity corresponds to the one chosen for the factors time series.

\subsection{Estimation of the indices' trend and volatility}

To estimate the trend and the volatility we assume that the period $s$ distribution for the index value $i_{\mathrm{s}}$ is a log-normal distribution. The expected mean of logs is:

$$
\hat{m}=\frac{1}{S} \sum_{s=1}^{S} \ln \left(\frac{\hat{\imath}_{s}}{\hat{\imath}_{s-1}}\right)
$$

The return volatility is:

$$
\hat{\sigma}^{2}=\frac{1}{S-1} \sum_{s=1}^{S}\left[\ln \left(\frac{\hat{\imath}_{s}}{\hat{\imath}_{s-1}}\right)-\hat{m}\right]^{2}
$$

The Brownian's trend is then estimated as follows:

$$
\hat{\mu}=\hat{m}+\frac{1}{2} \hat{\sigma}^{2}
$$

\section{The database}

\subsection{Description}

To compare empirically the impact of revision on these two repeat sales indices, we have constructed a database for Paris and its suburbs with two sources: the real estate price returns for each transaction and the corresponding computed returns from the economic and financial variables needed for the PCA factorial index.

The real estate price returns are extracted from the CD-Bien database which lists all real estate transactions written in front of a notary for Paris. From this database, we extracted 1082 transactions of commercial properties (office and professional activities) for which we had the information on both the initial price and date (posted $1^{\text {st }}$ of January 1982) at which the properties had been bought (date 1 , 
$T_{1}$ ) as well as the price and date (date $2, T_{2}$ ) for the following resale. To every observation in the database, we associate the holding period (duration) which corresponds to the difference $T_{2}-T_{1}$ expressed in days. These repeat measures transactions represent around $15 \%$ of the total number of transactions.

The economic and financial returns needed for the PCA factorial index are calculated from a series of indicators that one a priori believes to have some form of explanatory power of price changes. Nine variables were selected based on two criteria. The first one required that potential factors have a clear economic interpretation and presupposed links with real estate markets. The second was the availability of the data on the period running from $1^{\text {st }}$ of January 1982 . The indices selected to serve as factors were thus constructed with base 100 at the start of 1982. They are the following:

1. Savings as a percentage of disposable income: Datastream France gross household saving index

2. Consumer price index: the INSEE (the French National Statistical office) consumer price index

3. Rents as measured by the OLAP residential reletting index ${ }^{3}$

4. Long-term interest rate: Datastream France zero coupon ten-year bond rate

5. Short-term interest rate ${ }^{4}$ : Datastream France zero coupon one-year bond rate

6. Demographic index: the INSEE regional population index for Ile-de-France

7. Listed real estate: Datastream index dedicated to the stocks of the largest listed real estate companies in France

8. Unemployment: the INSEE index for France (in rate)

9. MSCI equity market index: the MSCI index for stocks listed in France.

The whole set of rates was then transformed into periodical returns.

3

The OLAP (OLAP stands for Observatoire des Loyers de l’Agglomération Parisienne) residential reletting index is based on a large sample of apartments that are regularly surveyed for which new lettings are systematically documented in order to produce the Paris and close suburban areas rent index. Unfortunately such an index does not exist for commercial properties. As this index explains a significant part of the variance for all segments of real estate (not only for housing), it is used here for commercial properties.

4

For long-term and short-term interest rates, the series are calculated by applying the rates to a basis of 100 as of January 1982. The applied rate corresponds to the average of the day-to-day rates for the ten-year or one-year bonds and for a given period (month). 


\subsection{Database characteristics}

Figure 1 represents the distribution of transaction dates for repeat sales in the CD-Bien database (date1, date2). These two graphs have been established for 288 months (during the period 1982-2005) and we can observe that a lot of months (140) do not contain any resale. Moreover, no month contains more than 28 observations for date 1 or date 2. As can be seen in Figure 2, starting in January 1982, the database does contain an increasing number of acquisitions for which we do have a resell price and date. The graph represents the number of transactions when the periodicity of the index increases (from yearly to monthly). However, the database does not contain any resell date prior to January 1994. This particular feature of the CD-Bien database may potentially induce a form of bias in the sense that the proportion of long holding period transactions is over-represented in the data. But this bias is present for both indices. And the impact of this bias does not seem to be different for the WRS index than for the PCA factorial index if we consider their general trend or volatility (see Figure 5). Moreover to decrease the impact of this bias, we analyze the behavior of the indices on a shorter period 1991-2005. For this period, and as can be seen in Figure 3, the profile of the number of transactions is thus closer to what can be expected.

\section{Estimation of the parameters and results}

Two periods of estimation are considered in order to analyze the relative robustness of the two repeat sales indices. The first period, 1991-2005, includes buy and resell transactions for all the sub-periods (see Figure 3). At the opposite, the period 1982-2005 includes at the beginning a great number of subperiods without any resell transactions (as illustrated by Figures $1 \& 2$ ).

\subsection{Estimation of the parameters for period 1991-2005}

The mean $(m)$, the trend $(\mu)$ and the volatility $(\sigma)$ are computed for the two indices depending on the periodicity. All the values in Table 2 are expressed as annual measures. This table clearly shows the volatility of the WRS index is very sensitive to the periodicity because of the corresponding 
transactions volume. The smaller the number of transactions is for each period, the greater the volatility. The WRS index volatility which is equal to $12.27 \%$ for the annual index increases to $34.26 \%$ for the quarterly index and even to $112.41 \%$ for the monthly index. We definitely observe a well known problem of the repeat sales indices: the small amount of information (small transactions by period) implies a higher standard deviation of the parameters estimators. Figure 3 shows that a great number of sub-periods contains less than 10 observations. The volatility estimation is a combination of the real volatility and the estimators' standard deviations.

On the contrary, the estimation of the volatility is stable for the PCA factorial index, whatever the periodicity and thus, whatever the number of transactions per period. In fact, the robustness of the estimation can be explained by the number of variables on which the real estate return is regressed. The factorial methodology always proceeds to a regression on the same number of variables (in our case 9 factors corresponding to the same number of economic or financial variables). That is not the case for the WRS methodology, where the number of the variables for the regression is depending on the number of periods (from 9 to 180 depending on the periodicity for the period 1991-2005).

\begin{tabular}{lcccccc}
\hline \hline & \multicolumn{3}{c}{ WRS } & \multicolumn{3}{c}{ Factorial } \\
& \multicolumn{1}{c}{$m$} & $\mu$ & $\sigma$ & $m$ & $\mu$ & $\sigma$ \\
\cline { 2 - 7 } Bi annual & 0,0517 & 0,0574 & 0,1068 & 0,0565 & 0,0598 & 0,0814 \\
Annual & 0,0496 & 0,0571 & 0,1227 & 0,0587 & 0,0643 & 0,1056 \\
Semi annual & 0,0508 & 0,0627 & 0,1543 & 0,0568 & 0,0621 & 0,1037 \\
Quaterly & 0,0588 & 0,1174 & 0,3426 & 0,0553 & 0,0611 & 0,1079 \\
Bi mensual & 0,0500 & 0,1928 & 0,5344 & 0,0557 & 0,0616 & 0,1081 \\
Mensual & 0,0587 & 0,6906 & 1,1241 & 0,0544 & 0,0601 & 0,1074 \\
& & & & & & \\
\hline \hline
\end{tabular}

Table 2: parameters estimation according to the periodicity (period 1991:2005)

The bias for the volatility of the WRS index implies a bias for the trend. This bias seems to be weaker for the mean, which gives a more robust final index value estimation $\left(\hat{P}_{S}\right)$. However, the mean estimation is more robust for the factorial index. 
Moreover, the two indices diverge more and more in function of the periodicity. When the periodicity is bi-annual, annual or semi-annual the indices look similar. The main differences come from an initial deviation of the WRS index (few observations) that remains along the whole index (by construction, this effect is cumulative).

Looking at the graphs when the periodicity is large, the PCA factorial index could appear as a smoothing of the WRS index. In fact the PCA factorial index does not smooth the index. It is less sensitive to the number of observations, and that is why the volatility does not increase when the periodicity does. We can conclude the estimation of the volatility cannot be done from the WRS index when the number of observations is too small, and this is an important result if we think of possible optional derivatives with this index as an underlying index (see Baroni et al., 2008).

\subsection{Estimation of the parameters for period 1982-2005}

The existing bias in the construction of the WRS index creates also an estimation error for the trend of the index. If we consider the period 1982-2005, where the number of observations is very small at the beginning, the estimation of the mean $(m)$ computed from the WRS index is not constant and depends on the periodicity. The estimation is even twice lower when the periodicity is the month than for a two-year period (see Table 4). This can be observed in Figure 5 particularly for short periods (for a one-month period, the index and then the mean cannot be computed because there are periods without any observations). Inversely, for the PCA factorial index the estimation of the mean seems to be much more stable whatever the periodicity.

According to the trend, it cumulates the two biases (from both the mean and the volatility). As expected, the trend for the WRS index is strongly biased and the estimation seems to be irrelevant in the case of the periodicity inferior to the semester. 


\begin{tabular}{lcccccc}
\hline \hline & \multicolumn{3}{c}{ WRS } & \multicolumn{3}{c}{ Factorial } \\
& $m$ & $\mu$ & $\sigma$ & $m$ & $\mu$ & $\sigma$ \\
\cline { 2 - 7 } Bi-annual & 0,0659 & 0,0706 & 0,0970 & 0,0626 & 0,0688 & 0,1114 \\
Annual & 0,0650 & 0,0814 & 0,1811 & 0,0609 & 0,0653 & 0,0946 \\
Semi annual & 0,0507 & 0,0989 & 0,3102 & 0,0635 & 0,0670 & 0,0846 \\
Quarterly & 0,0345 & 0,2015 & 0,5778 & 0,0651 & 0,0618 & 0,0819 \\
Bi-monthly & 0,0500 & 0,4003 & 0,8537 & 0,0613 & 0,0646 & 0,0813 \\
Monthly & 0,0359 & 0,6906 & 1,1241 & 0,0604 & 0,0632 & 0,0754 \\
& & & & & & \\
\hline \hline
\end{tabular}

Table 4: parameters estimation according to the periodicity (period 1982:2005)

At the opposite for the PCA factorial index the trend $(\mu)$ is more stable and does not seem to be biased by the impact of small transactions when the periods are short. These results show the robustness of the PCA factorial index and of the estimation of the parameters.

We can also notice in Figure 5 especially for the semi-annual index, that when the WRS index deviates from its path in the first periods, it cannot join it again for the other period. And on the whole, its mean is underestimated.

According to the volatility, the results for the WRS index are similar than those presented in section 3.1, but the volatility for the PCA index is lightly decreasing with the periodicity (as already noticed in Baroni et al., 2008). This feature could be explained by the structure of the dataset in the sense that there are no resell transactions before 1991.

\section{Conclusion}

In this paper we underlined the lack of robustness of the WRS index when the number of transactions is small. This is an important limit of this methodology which prevents its use for short periodicity or little cities or districts. It has also consequences on the estimation of the trend and the volatility that can be computed from the index. These parameters cannot be correctly estimated and the measures are not stable if the periodicity changes. In the case of small dataset, we suggested to use a PCA factorial methodology which can lead to a more robust index, less dependent on the number of transactions of 
each period. The trend and the volatility measured from this index are stable if the periodicity increases and seem to be much better estimated. Even if a further research could determine if an optimal periodicity exists to measure these parameters, the results of our study already show that it is possible to measure them with a certain degree of confidence whatever the chosen periodicity. 


\section{REFERENCES}

Abraham, J. and W.S. Schauman (1991), New Evidence on Home Prices from Freddie Mac Repeat Sales, AREUEA Journal, 19(3), 333-352.

Bailey. M.J., R.F. Muth and H.O. Nourse (1963), “A Regression Method for Real Estate Price Index Construction”, Journal of the American Statistical Association, Vol. 58 (304). 933-942.

Baroni, M., Barthélémy F., and M. Mokrane (2001), “Physical Real Estate: Risk Factors and Investor behaviour, Working Paper DR 0120 Essec Business School, Paris \& THEMA Working Paper.

Baroni. M., F. Barthélémy and M. Mokrane (2005), "Real Estate Prices: A Paris Repeat Sales Residential Index”, Journal of Real Estate Literature, 13 (3). 303-321.

Baroni. M., F. Barthélémy and M. Mokrane (2007), “A PCA Factor Repeat Sales Index For Apartment Prices in Paris”, Journal of Real Estate Research, 29 (2), 137-158.

Baroni. M., F. Barthélémy and M. Mokrane (2008), "Is it possible to construct derivatives for the Paris residential market?”, Journal of Real Estate Finance and Economics, DOI 10.1007/s11146008-9114-6

Case, K. E., H. O. Pollakowski and S. M. Watcher (1997), “Frequency of Transaction and House Price Modelling”, Journal of Real Estate Finance and Economics, (14), 173-187.

Case, K. E., and R. J. Shiller (1987), "Prices of single Family Homes since 1970: New Indexes for four Cities”, New England Economic Review, September/October 1987, 45-56.

Case, K. E., and R. J. Shiller (1989), “The Efficiency of the Market for Single Family Homes”, American Economic Review, Vol. 79 (1), 125-137.

Clapp, J. M., and C. Ciaccotto (1992), "Repeat Sales Methodology for Price Trend Estimation an Evaluation of Sample Selectivity”, Journal of Real Estate Finance and Economics, (5), 357-374.

Clapp, J. M., and C. Ciaccotto (1999), "Revisions in Repeat-Sales Price Indexes: here today, gone tomorrow?”, Real Estate Economics, 27(1), 79-104.

Clapham E., P. Englund, J. Quigley and C. Redfearn (2006), "Revisiting the Past and Setting the Score: index Revision For House Price Derivatives”, Real Estate Economics, Vol. 34 (2). 275-302.

David, A., F. Dubujet, C. Gourriéroux, and A. Laferrère (2002), “Les Indices de Prix des Logements Anciens”, INSEE Méthode, $\mathrm{n}^{\circ} 98$.

Englund, P., J. M. Quigley, and C. L. Redfearn (1998), “Improved Price Indexes for Real Estate: Measuring the Course of Swedish Housing Prices”, Journal of Urban Economics, 44, 171-196. 
Gatzlaff, D., and D. Haurin (1997), “Sample Selection Bias and Repeat-Sales Index Estimates”, Journal of Real Estate Finance and Economics, 14, 33-50.

Goetzmann, W. (1992), “The Accuracy of Real Estate Indices: Repeat Sales Estimators”, Journal of Real Estate and Economics, 5, 5-53.

Goetzmann, W., and M. Spiegel (1995), "Non-temporal Components of Residential Real Estate Appreciation”, Review of Economics and Statistics, 77(1), 199-206.

Goodman, A. C., and T. G. Thibodeau (1995), “Age Related Heteroskedasticity in Hedonic House Price Equations”, Journal of Housing Research, 6, 25-42.

Goodman, A. C., and T. G. Thibodeau (1998), “Dwelling Age Heteroskedasticity in Repeat Sales House Price Equations”, Journal of Housing Research, 26, 151-171.

Greene, W. H. (1997), Econometric Analysis, Prentice Hall Fourth edition.

Hwang, M., and J. M. Quigley (2004), "Selectivity Quality, Adjustement and Mean Reversion in the Measurement of House Values”, Journal of Real Estate Finance and Economics, 28, 161-178.

Maurer, R., Pitzer M., and Sebastian S. (2001), “Construction of a Transaction Based Real Estate Index for the Paris Housing Market”, Johann Wolfgang Goethe-Universität Frankfurt Working Paper.

McMillen, D.P., and J. Dombrow (2001), “A Flexible Fourier Approach to Repeat Sales Price Indexes”, Real Estate Economics, 29 (2), 207-225.

Meese, R. A., and N. F. Wallace (1997), “The Construction of Residential Housing Price Indices: A Comparison of Repeat- Sales, Hedonic-Regression, and Hybrid Approaches”, Journal of Real Estate Finance and Economics , 14 (1\&2), 51-73.

Meese, R. A., and N. F. Wallace (1998), “Dwelling Price Dynamics in Paris, France”, Berkeley Program on housing and Urban Policy, Working Paper Series, W98-003.

Quigley, J. M. (1995), “A Simple Hybrid Model for Estimating Real Estate Price Indices”, Journal of Housing Economics, 4, 1-12.

Shiller, R. (1998), Macro Markets, Creating Institutions for Managing Society's Largest Risks, Clarendon Lectures in Economics, Oxford University Press.

Spanos A. (1999) , "Probability Theory and Statistical Inference”, Cambridge University Press.

Thion, B., P. Faverger, and M. Hoesli (2001), “Indices des Ventes Répétées et Modifications de l’Environnement Immobilier”, Working Paper, HEC Genève, 11. 
Webb, C. (1981a), “The Expected Accuracy of A Real Estate Price Index”, Chicago State University Working Paper, Department of Mathematics.

Webb, C. (1981b), “Trading Activity and the Variance of an Index Number”, Chicago State University Working Paper, Department of Mathematics. 


\section{Figures}
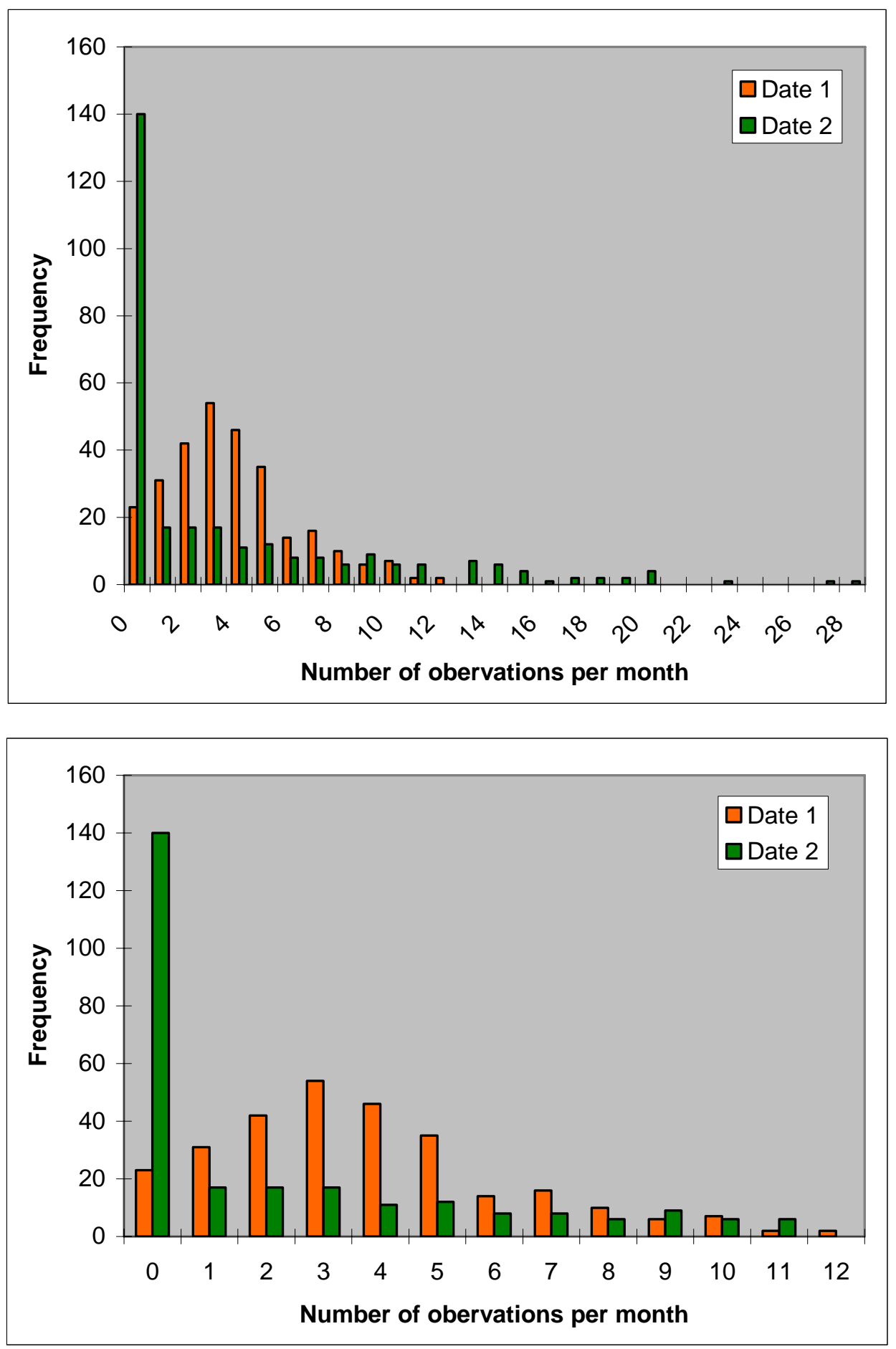

Figure 1: Date 1 and Date 2 monthly repartition for the period 1982:2005 


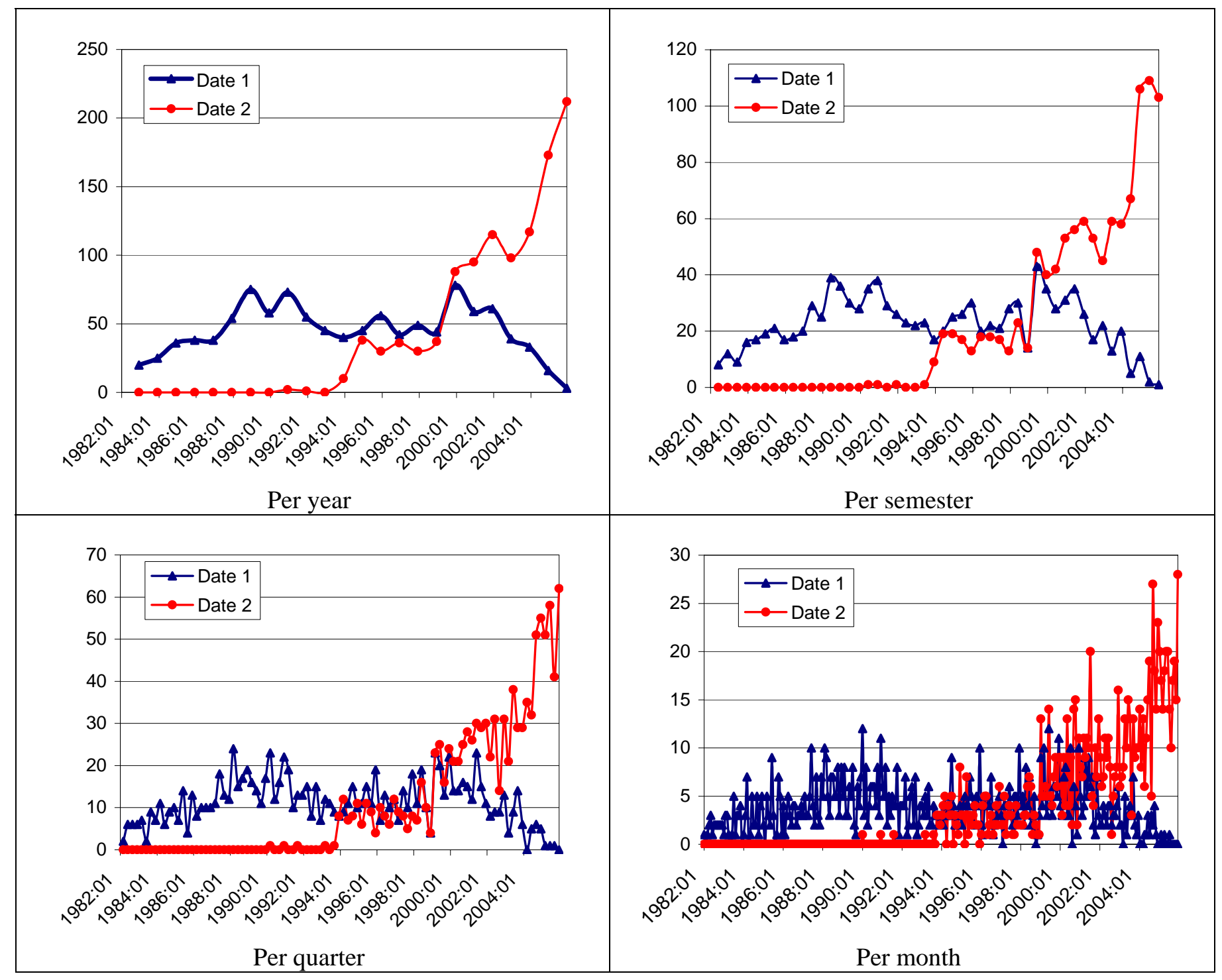

Figure 2: Date 1 and Date 2 repartitions across periods 1982:2005 


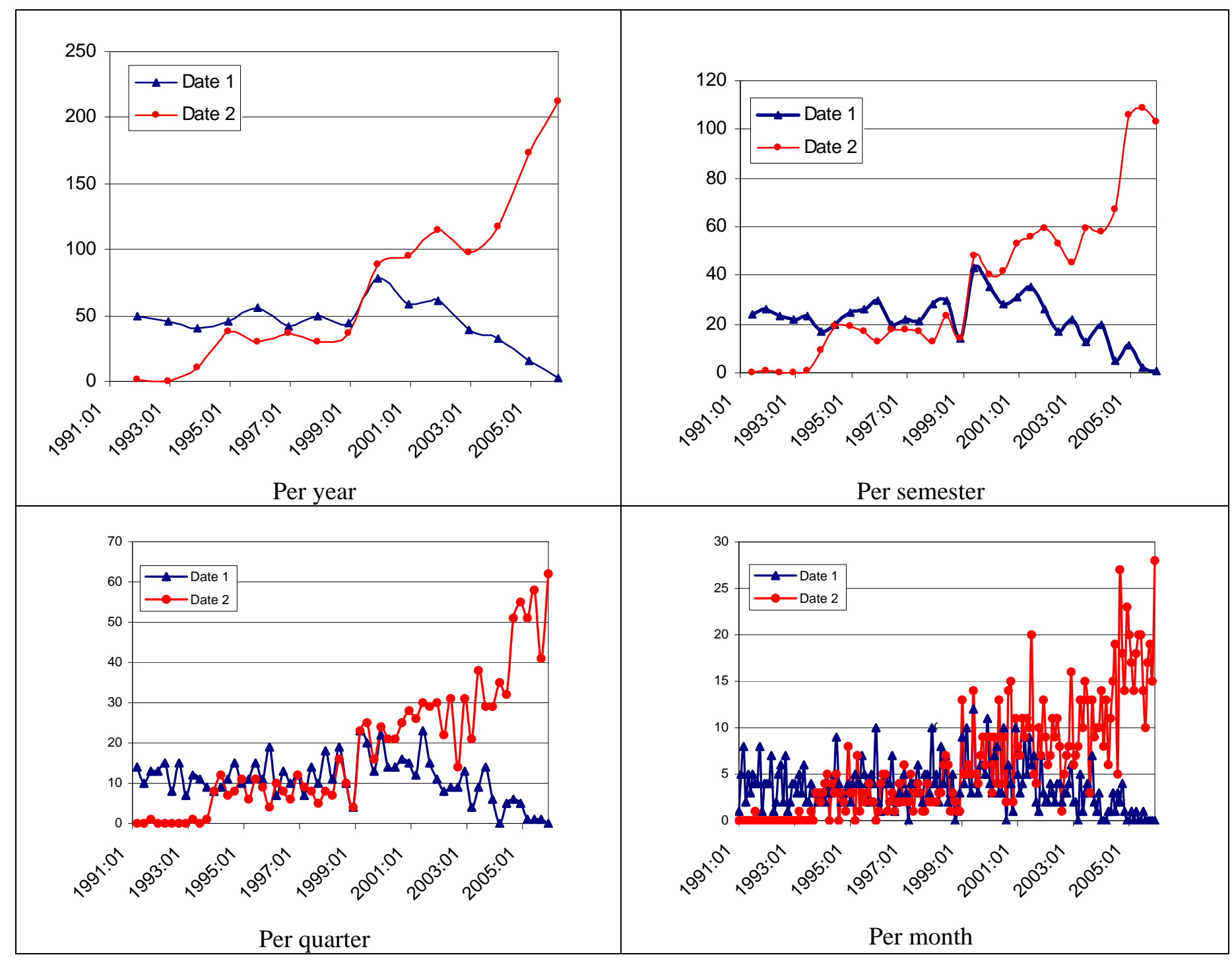

Figure 3: Date 1 and Date 2 repartitions across periods 1991:2005 


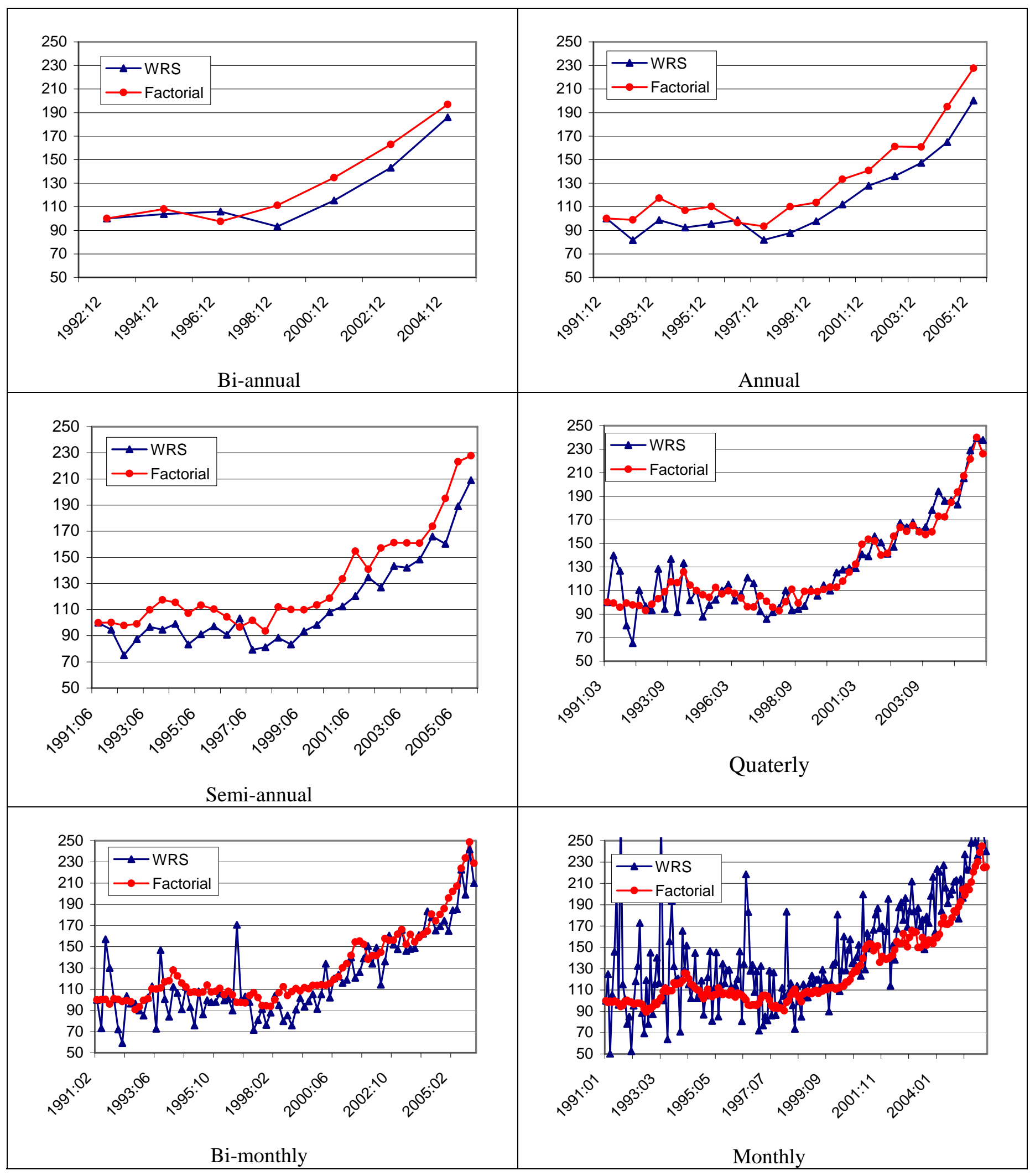

Figure 4: WRS and Factorial indices for the period 1991:12-2005:12 


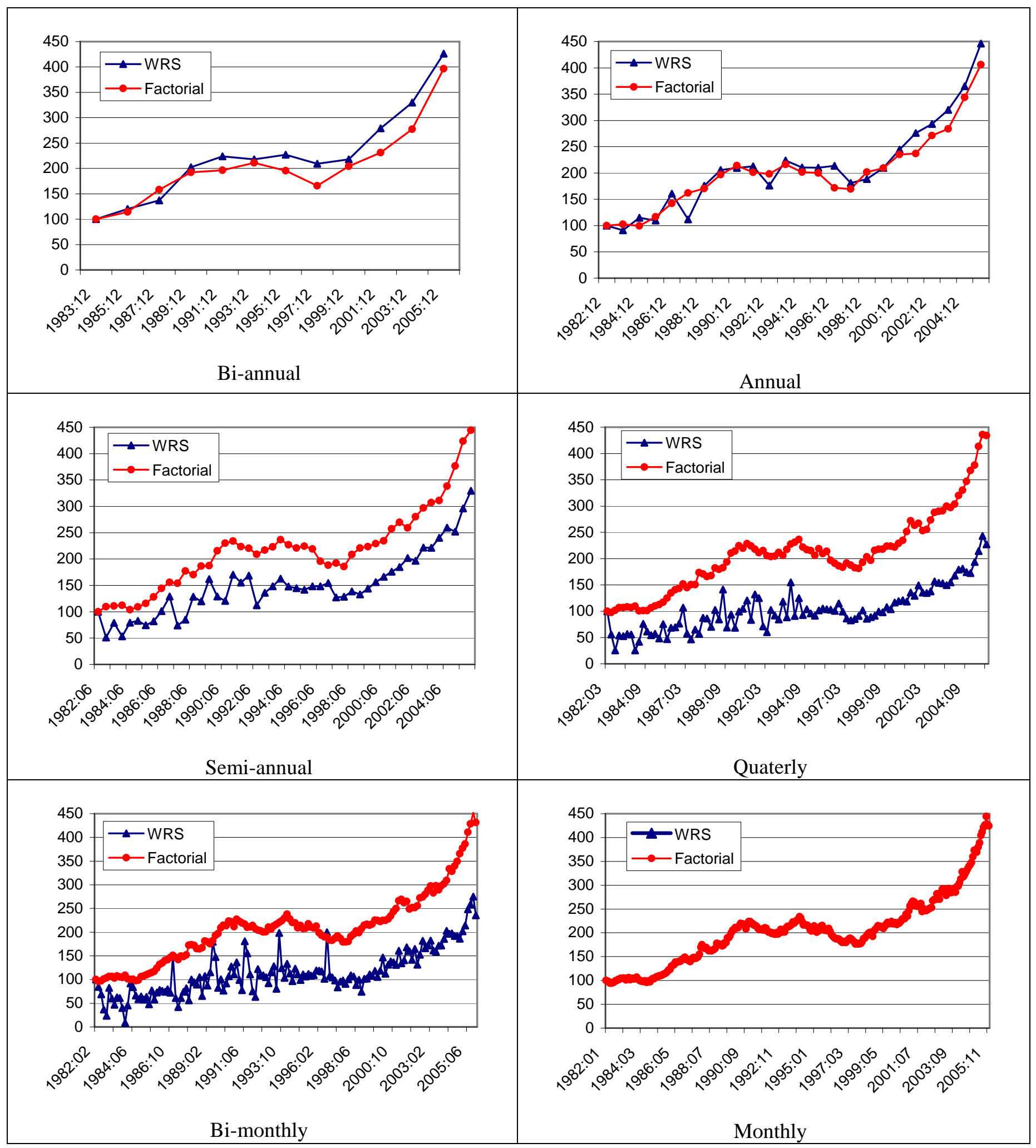

Figure 5: WRS and Factorial indices for the period 1982:12-2005:12 